\title{
The difference in scales in educational improvisation, solfege, and kinetic
} rhythm

Fatima Mahmoud Al-Jarsha

$$
\begin{aligned}
& \text { الملغص: } \\
& \text { يبنـى الارتجـال الموسـيقي علـى ثلانــة عناصـر هـي ( الإيقـاع / اللــن / الهـارموني ) }
\end{aligned}
$$

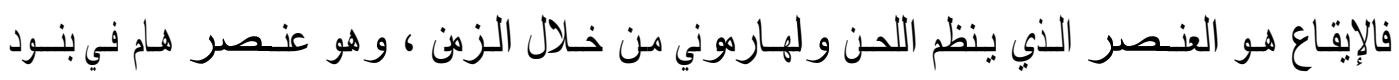

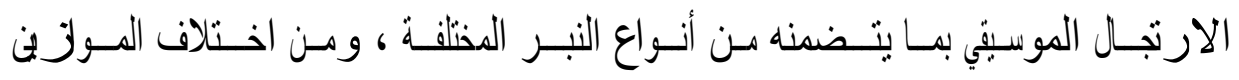

$$
\begin{aligned}
& \text { وتعددها أو تعدد الإيقاعات وتتو عها ، أو استخدام السر عات المختلفة. } \\
& \text { والارتجال الموسيقي أسسيًا في في مصاحبة التمرينات الصولفائية وفي عزف الققلات التي تحتّاج إلى }
\end{aligned}
$$

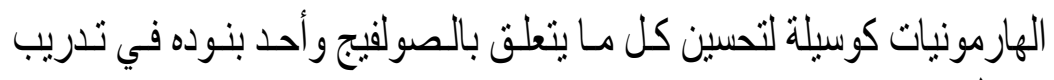

$$
\begin{aligned}
& \text { السمع. }
\end{aligned}
$$

\section{Abstract:}

Musical improvisation is built on three elements (rhythm / melody / harmonic)

Rhythm is the element that regulates the melody and the harmonica through time, and it is an important element in the terms of musical improvisation, including all kinds of variations

The multiplicity of them, the multiplicity and diversity of rhythms, or the 
use of different speeds.

Musical improvisation is essential in the accompaniment of Solfej exercises and in playing the harmonium-needed locks as a way to improve everything related to Solfege and one of its items

Hearing.

مقدمة :

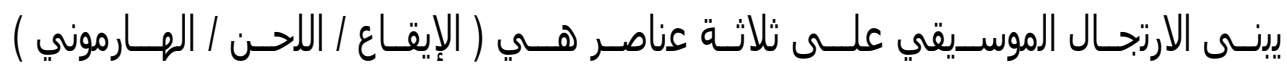

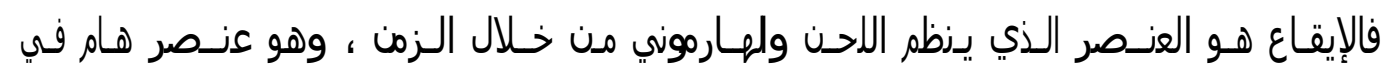

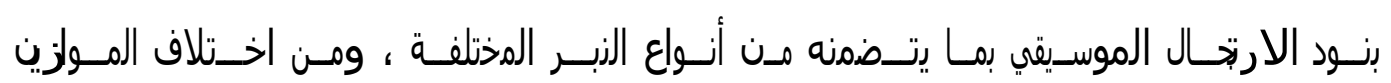

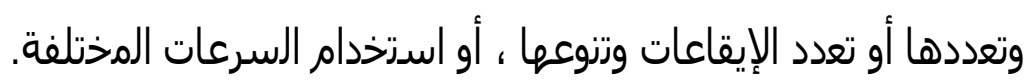
والارتجال الموسيقي أساسيًا في في مصاحبة الرمرينات الصولفائية وفي عـزف القفلات التي

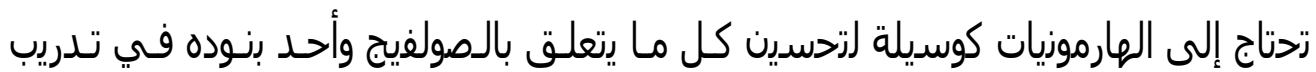

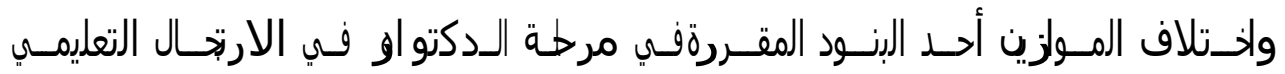

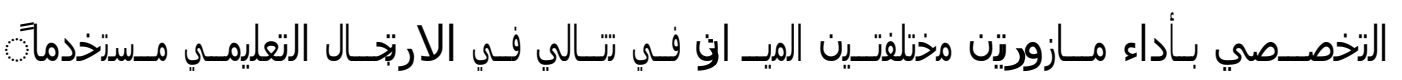
وسائل التحويل البعيدة بنفس الإيقاع كما في الشكل التالي :
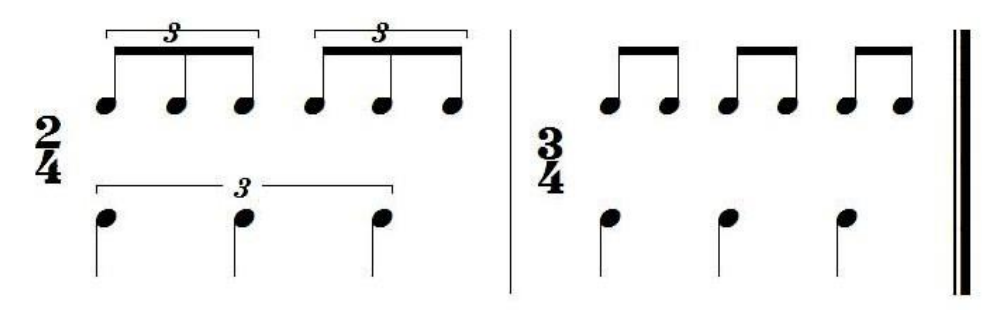

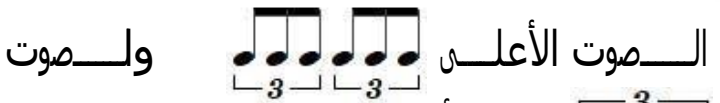

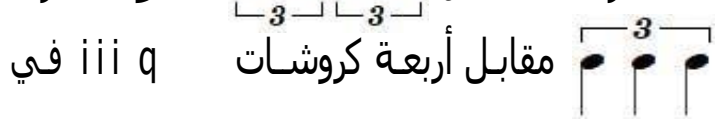

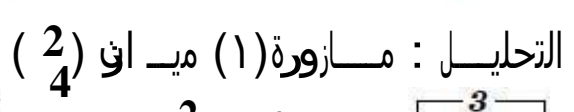

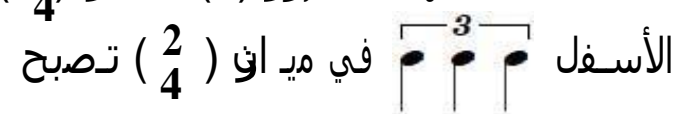




$$
\text { مي ان } 2 \text { ل رتصبح } 3 \text { مقابل } 4 .
$$

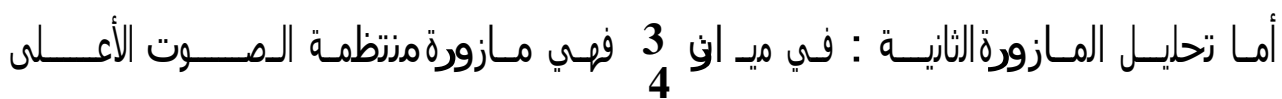

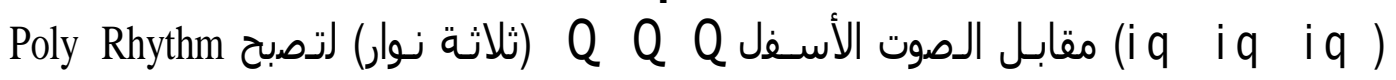

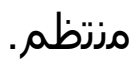

1- أميمة أمين - عائشة سليم : رينابيع الأفكار الموسيقية لتعليم الارتحالات الموسيقية ، القاهرة: مكتبة الأزجلو ، (199 ، ص

.r. 


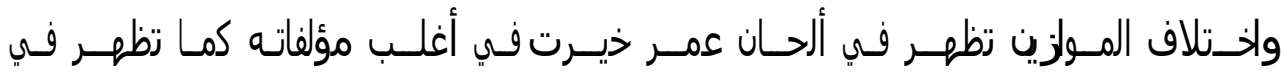
مقطوعة (ص اه الأحفاد) هكذا
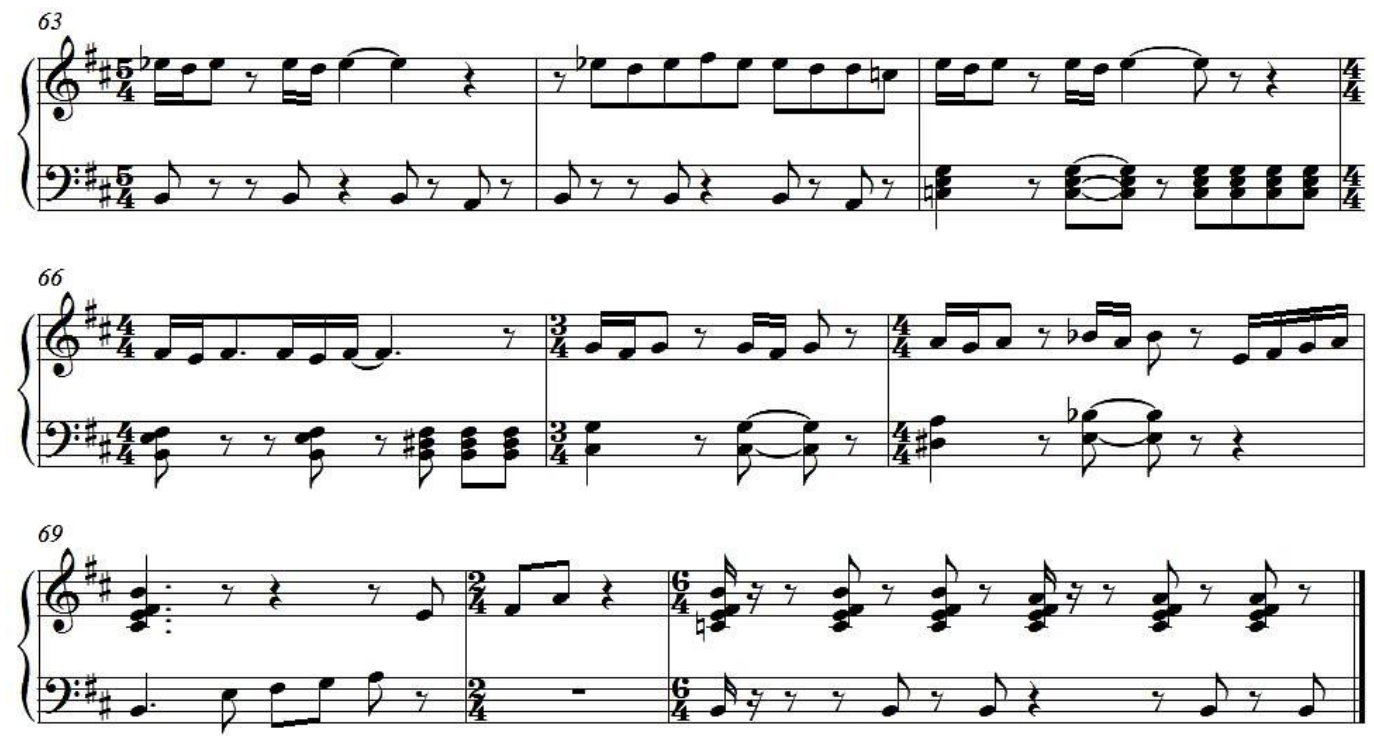

وتظطر مثال لاختلاف الموازين مقطوعة بعنوان (Piano Moods) هكذا :
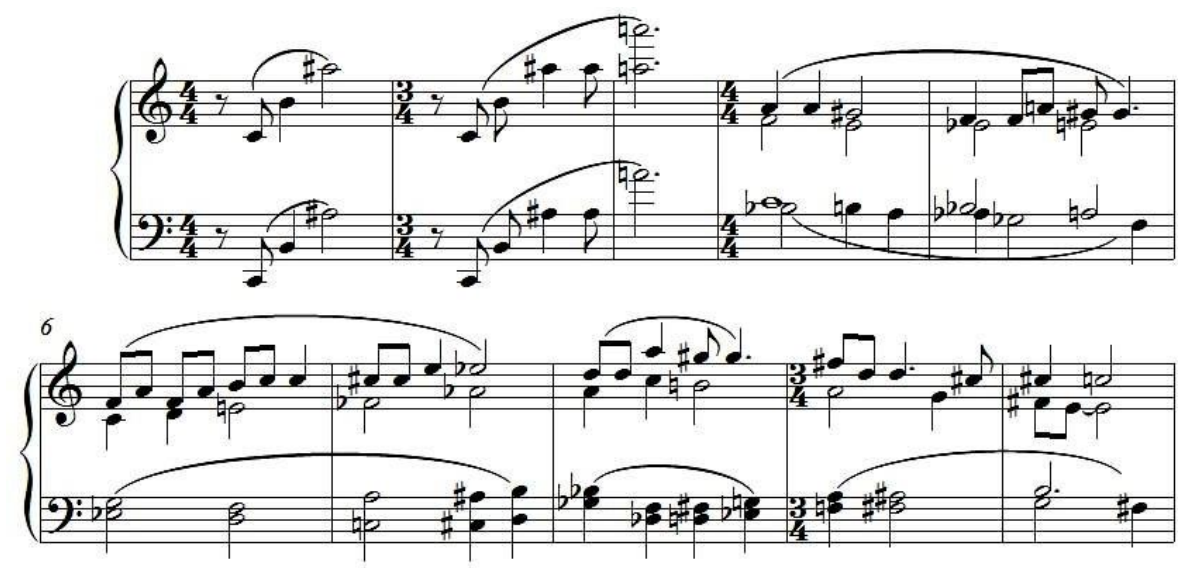

وهناك ما يعرف في المؤلفات الحديثة بتعدد الموازين (Poly Metric).

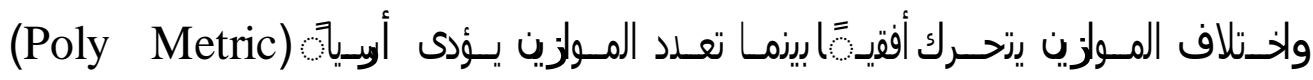

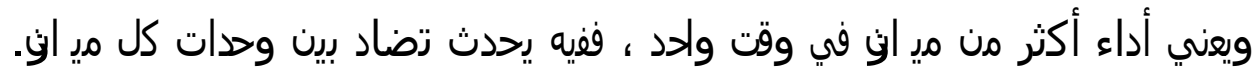

' : زوتعدد الموازين (Poly Metric)

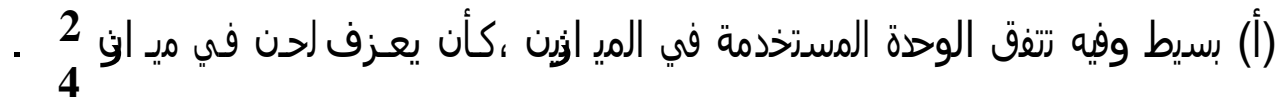
في وقت عزف لحن آخر في مي او 3 •. مثال :

1ـــ أميمة أمين ، عائثة سليم : الموضوعات الدالكروزية بين النظرية والتطبيق في الإيقـاع الحركـي ، القـاهرة : مكتبـة الأنجلـو ،

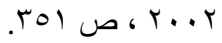




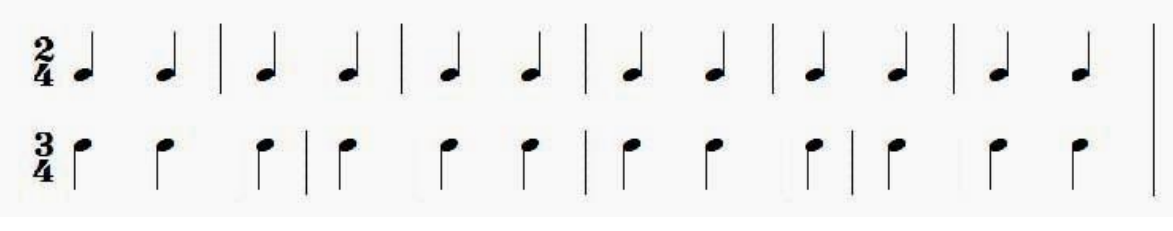

(ب) معقد وفيه تختلف الوحات المسرخدمة في المي ان مثال :

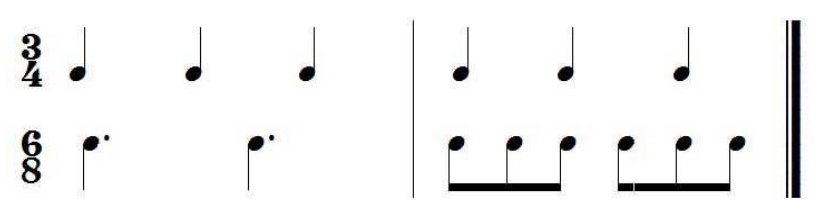

وفي هذا الأداء يزتج مـا يعرف بالمقابلات الإيقاعية يكون الناتج السمعي مـا يسمى ؟

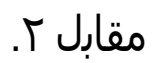
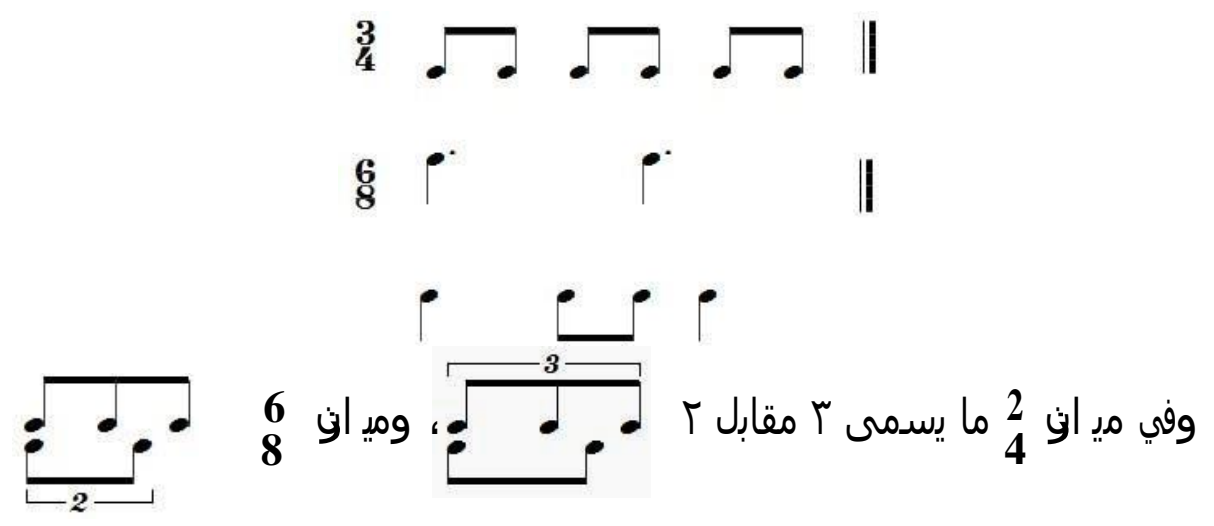

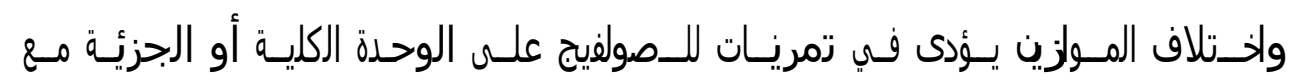
وجود إيقاعات شاذة تؤدى في صورةمقابلات إيقاعية. مثال لاختلاف الموازين في الصولفيج :

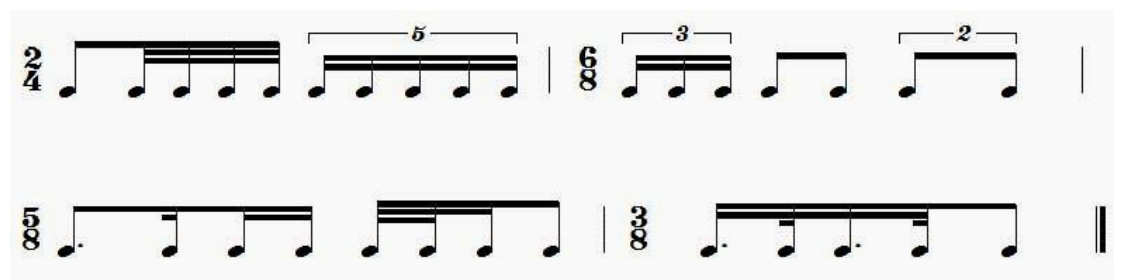

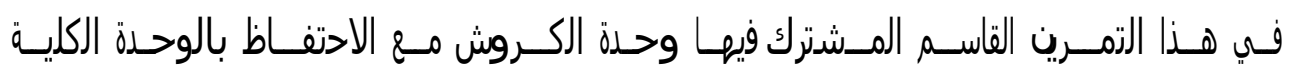

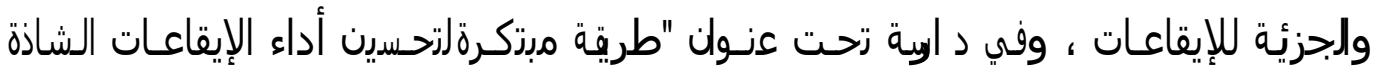

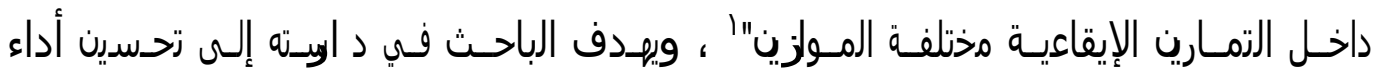

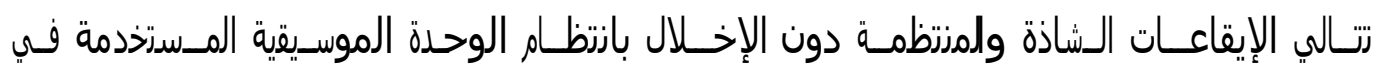

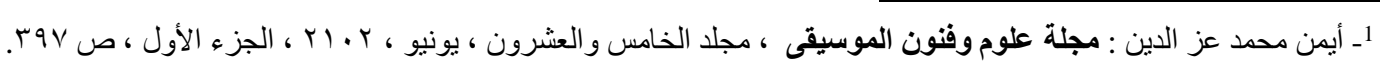




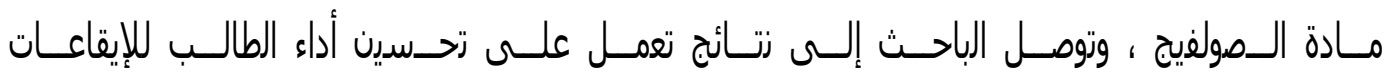
الشاذة داخل التمارين الإيقاعية المرتوعة.

ويظهر اختلاف الموازين في الإيقاع الحركي متى يعرف بالرمرين الشامل الذي يؤدى في صيغة (الروزدو)" ، مثال لاختلاف الموازين في الإيقاع الحركي :

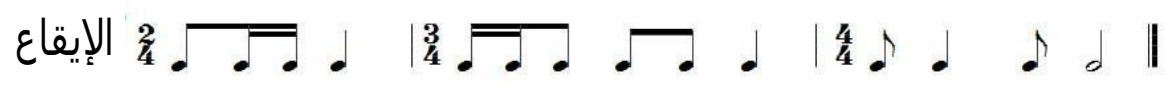

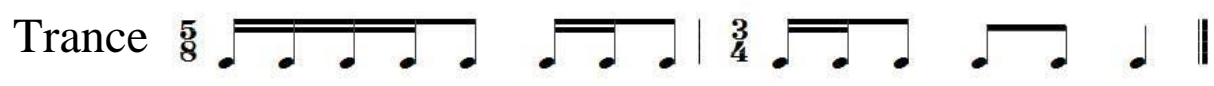

Poly

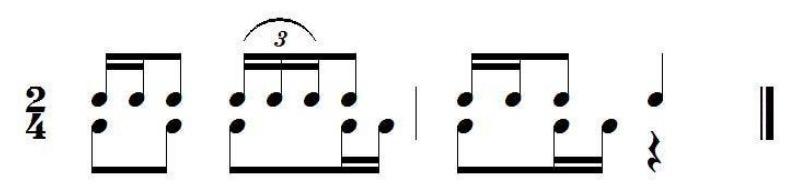

ولإتقان اختلاف الموازين فـي مــواد التخصص (الارتجـال والـصولفيج والإيقـاع) لابـد مـن إتقــان

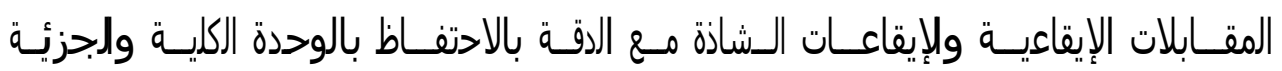

للإيقاعات.

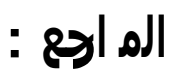

ا- أميمة أمين ، عائشة سليم : الموضوعات الدالكروزية بِين الزظرية والزطبيق في الإيقاع

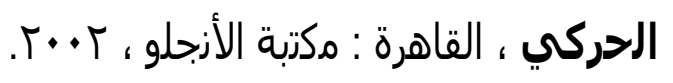

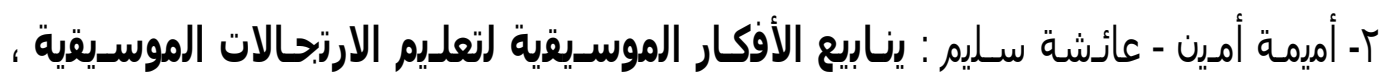

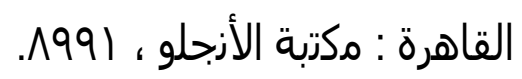

ז- أيمـن محمـد عـز الـدين : محلة علـوم وفنون الموسيقى ، مجلد الخـامس والعشرون ،

$$
\text { يوزيو ، ؟ •اب ، الجزء الأول. }
$$

